

\title{
Mn-SOD 47 CC genotype in combination with high tea consumption may prevent complications in Tunisian type-2 diabetes
}

H. Abaidi ${ }^{1}$, S. Denden ${ }^{2}$, A. Ghazouani ${ }^{1}$, A. Trimèche ${ }^{3}$, C. Snoussi ${ }^{1}$, A. Haj Khelil' ${ }^{2}$ J. Ben Chibani ${ }^{2}$ and M.H. Hamdaoui ${ }^{1}$

${ }^{1}$ Research Unit on Antioxidant Compounds, Oxidative Stress, Trace Elements and Metabolic Diseases, High School of Health Sciences of Tunis, University of Tunis, El Manar, Tunis, Tunisia

${ }^{2}$ Research Unit of Biology and Molecular Anthropology Applied to Development and Health, Faculty of Pharmacy of Monastir, Monastir, Tunisia ${ }^{3}$ National Institute of Nutrition and Food Technology, Tunis, Tunisia

Corresponding author: H. Abaidi

E-mail: h.abaidi@yahoo.fr

Genet. Mol. Res. 14 (3): 8613-8622 (2015)

Received September 3, 2014

Accepted March 18, 2015

Published July 31, 2015

DOI http://dx.doi.org/10.4238/2015.July.31.9

ABSTRACT. Reactive oxygen species metabolizing enzymes may play an important role in the prevention of type-2 diabetes (T2D) complications. We analyzed the association between $\mathrm{Cu} / \mathrm{Zn}-\mathrm{SOD}$ $+35 \mathrm{~A} / \mathrm{C}$, Mn-SOD T47C, and CAT $-21 \mathrm{~A} / \mathrm{T}$ gene polymorphisms and complications, in combination with tea consumption in Tunisian T2D. A sample of 366 T2D subjects was enrolled in this study. All participants were asked about tea consumption and frequency. Anthropometric, clinical, and routine biochemical characteristics were obtained from subjects' updated medical records. Malondialdehyde, as an early marker of lipid peroxidation, was measured in plasma samples. Urinary polyphenol derivatives (UPDs), as a marker of polyphenols intake, were assessed by the Folin-Ciocalteu assay. SODs and CAT 
genotypes were determined by conventional restriction fragment length polymorphism-polymerase chain reaction (RFLP-PCR) methods. From all subjects, the results showed that in high tea consumers ( $>3$ cups/ day), the frequency of the Mn-SOD 47 CC genotype was significantly higher in T2D without complications compared with T2D with complications $(\mathrm{P}=0.03 ; \mathrm{OR}=0.284 ; 95 \% \mathrm{CI}=0.086-0.939)$. However, no significant associations were observed with $\mathrm{Cu} / \mathrm{Zn}-\mathrm{SOD}+35 \mathrm{~A} / \mathrm{C}$ or CAT $-21 \mathrm{~A} / \mathrm{T}$ genes polymorphisms. Additionally, the evaluation of UPDs showed that individuals carrying the Mn-SOD 47 CC genotype and consuming more than three cups of tea per day present significantly higher UPDs $(\mathrm{P}=0.038)$. In conclusion, the Mn-SOD $47 \mathrm{C}$ variant in combination with high tea consumption may provide protection against complications in T2D.

Key words: SODs and CAT polymorphisms; Tea intake; Urinary polyphenol derivatives; Type-2 diabetes complications; $\mathrm{T} 2 \mathrm{D}$ complications

\section{INTRODUCTION}

As with other multifactorial diseases, type 2 diabetes (T2D) is mostly the result of interaction between both genetic and clinical factors such as oxidative stress (Villeneuve and Natarajan, 2010). Oxidative stress is defined as a disturbance in the balance between the production of reactive oxygen species (ROS) and antioxidant defenses, including enzymatic and non-enzymatic systems (Poljsak et al., 2013). Implication risk of T2D is closely associated with oxidative stress, which is a link between disease and long-term diabetes complications (Aditi et al., 2013). There is evidence indicating that oxidative stress is associated with renal damage, cardiovascular morbidity, and mortality (Ascencio-Montiel et al., 2013). The antioxidant enzyme pathway is the primary defense against ROS-induced damage (Guérin et al., 2001). Genetic variations in the antioxidant genes coding for the superoxide dismutase (SOD), CAT, and GPX enzymes may impair the regulation of enzymatic activities and ROS elimination. Thus, genetic variations in antioxidant enzymes could modulate disease risk (Forsberg et al., 2001). The potential involvement of SOD and CAT polymorphisms in susceptibility risk of developing diabetes and its complications has been reported elsewhere, but not in Tunisian T2D (Dutkiewicz et al., 2010; Kariž et al., 2012). A meta-analysis showed a significant association of the T47C C allele of Mn-SOD with reduced risk of diabetic microvascular complications including diabetic nephropathy, diabetic retinopathy, and diabetic polyneuropathy in dominant, recessive, and codominant models (Tian et al., 2011). The SODs are a class of enzymes involved in the detoxification of superoxide into hydrogen peroxide (Montano et al., 2012). Three major isoforms of SOD have been identified according to their tissue location and transition metals. $\mathrm{Cu} / \mathrm{Zn}$-SOD essentially resides in the cytoplasm, Mn-SOD in the mitochondria, which is the major site for the manufacture of ROS, and ecSOD is extracellular (Neves et al., 2012; Crawford et al., 2012). CAT regulates the metabolism of hydrogen peroxide by decomposing it into water and oxygen (Zhang et al., 2011).

Nowadays, more attention is focused on tea consumption because both green and black teas contain numerous ingredients, such as polyphenolic compounds, that enable better 
control of the T2D pathway, especially insulin resistance (Bahadoran et al., 2013). In previous meta-analyses of the EPIC-InterAct case-cohort study conducted in 26 centers in eight European countries and consisting of a total of 16,835 T2D individuals, tea consumption was inversely associated with incidence of T2D. Indeed, a linear inverse association was observed between tea consumption and incidence of T2D. People who drink at least four cups of tea per day may have a 16\% lower risk of developing T2D than non-tea drinkers (InterAct Consortium et al., 2012). Therefore, an investigation of the beneficial effects of the combination of polymorphism in antioxidant enzymes and tea consumption could have great practical importance in medical T2D care.

The purpose of the current study was to assess the association between $\mathrm{Cu} / \mathrm{Zn}-\mathrm{SOD}$, Mn-SOD, and CAT gene polymorphisms $[+35 \mathrm{~A} / \mathrm{C}$ in the $\mathrm{Cu} / \mathrm{Zn}-\mathrm{SOD}$ gene (rs2234694), T47C in the Mn-SOD gene (rs4880), and -21 A/T in the CAT gene (rs7943316)] and T2D complications in moderate and high tea consumers. In addition, we investigated whether these allelic variants of the SOD and CAT genes were correlated with levels of urinary polyphenol derivatives (UPDs) (a marker of polyphenols intake) in moderate and high consumers of tea.

\section{MATERIAL AND METHODS}

\section{Patients}

This study enrolled a total of 366 adults with T2D. Patients were recruited randomly from different consulting services of the National Institute of Nutrition in Tunis. This research was approved by the local Ethics Committee and written consent was obtained from patients. Anthropometric, clinical, and biochemical characteristics, and types of complication or associated pathologies were obtained from the updated medical records of all subjects. For tea consumption, all participants were asked about the type of tea (green or black) and the number of cups consumed daily (mean cup serving, $35 \mathrm{~mL}$ ). Green tea was majorly consumed (up to $80 \%$ of cases) in the form of a decoction + sugar or sweetener, which is a popular beverage in Tunisia and in other North African countries. It has been demonstrated that decoctions from green or black tea provide high polyphenols content (Dhaouadi et al., 2010). The green tea decoction was characterized by the brewing of the dried tea leaves in boiling water for a variable period of time, not exceeding 60 min overall. However, tea infusions consumed in most Western countries are prepared by adding a proportion of $\sim 1 \mathrm{~g}$ leaf to $100 \mathrm{~mL}$ hot water and letting it brew for about $3 \mathrm{~min}$. A subdivision of subjects was performed according to tea intake frequency: moderate tea consumers $(<3$ cups/day, $\mathrm{N}=226)$ and high consumers $(>3$ cups/day, $\mathrm{N}=140$ ).

\section{Biochemical analyses}

Patients' routine biochemical parameters were identified from their updated medical records. Blood (3-5 mL) was collected in an ethylenediaminetetraacetic acid-containing tube. The plasma obtained was used for the determination of malondialdehyde assay (MDA), as an early marker of lipid peroxidation, according to the Ohkawa et al. (1979) method. Additionally, about $5 \mathrm{~mL}$ urine was collected to measure UPDs. The extraction of polyphenols from urine was performed according to the method used by Dhaouadi et al. (2010). UPD level was estimated spectroscopically by the Folin-Ciocalteu assay described by Singleton and Rossi (1965). 


\section{Genotyping}

Genomic DNA was isolated from blood samples, taken in ethylenediaminetetraacetic acid, using an innuPREP Blood DNA Mini Kit (Analytik Jena AG, Thuringia, Germany). Determination of the SOD and CAT polymorphisms was achieved by restriction fragment length polymorphism-polymerase chain reaction (RFLP-PCR) analysis using the primers and the restriction enzymes shown in Table 1. PCR was carried out in a final volume of $25 \mu \mathrm{L}$, using $1 \mu \mathrm{L} 100 \mathrm{ng}$ genomic DNA, 0.2 U Taq DNA polymerase (Analytik Jena AG), $2.5 \mu \mathrm{L}$ $10 \mathrm{X}$ buffer, $0.2 \mathrm{mM}$ dNTP, $0.4 \mu \mathrm{M}$ of each of the primers, and $1.5 \mathrm{mM} \mathrm{MgCl}_{2}$. PCR cycles were carried out in a DNA Thermal Cycler (MultiGene, Labnet) according to the following program: an initial denaturation of DNA at $94^{\circ} \mathrm{C}$ for $5 \mathrm{~min} ; 35$ cycles of $1 \mathrm{~min}$ at $94^{\circ} \mathrm{C} ; 30 \mathrm{~s}$ at $59^{\circ} \mathrm{C}$, or $57^{\circ} \mathrm{C}$, or $60^{\circ} \mathrm{C}$ to detect $\mathrm{Cu} / \mathrm{Zn}-\mathrm{SOD}+35 \mathrm{~A} / \mathrm{C}, \mathrm{Mn}-\mathrm{SOD} \mathrm{T} 47 \mathrm{C}$, or CAT $-21 \mathrm{~A} / \mathrm{T}$ polymorphisms, respectively; and $45 \mathrm{~s}$ at $72^{\circ} \mathrm{C}$. A final extension was performed at $72^{\circ} \mathrm{C}$ for $7 \mathrm{~min}$. The resulting PCR products were digested with the corresponding restriction endonucleases: $5 \mathrm{U} H h a \mathrm{I}$ (Thermo Scientific), $2.5 \mathrm{U}$ BsawI (New England BioLabs), and 5 U HinfI (Jena Bioscience) according to the manufacturer recommendations. Digestion products were analyzed electrophoretically on $3 \%$ agarose gel stained with ethidium bromide.

Table 1. Primers and restriction fragment length polymorphism-polymerase chain reaction conditions used for detection of the $\mathrm{Cu} / \mathrm{Zn} \mathrm{SOD}+35 \mathrm{~A} / \mathrm{C}$, Mn-SOD C47T, and CAT $-21 \mathrm{~A} / \mathrm{T}$ polymorphisms.

\begin{tabular}{|c|c|c|c|c|}
\hline Polymorphism & Primers & $\begin{array}{l}\text { Restriction } \\
\text { enzymes }\end{array}$ & $\begin{array}{l}\text { Annealing } \\
\text { temperature }\end{array}$ & Restriction fragments \\
\hline $\mathrm{Cu} / \mathrm{Zn} \mathrm{SOD}+35 \mathrm{~A} / \mathrm{C}$ & $\begin{array}{l}\text { 5'-CTATCCAGAAAACACGGTGGGCC-3' } \\
\text { 5'-TCTATATTCAATCAAATGCTACAAAAC-3' }\end{array}$ & HhaI & $59^{\circ} \mathrm{C}$ & $\begin{array}{l}\text { C allele } 71 \text { and } 207 \mathrm{bp} \\
\text { A allele } 278 \mathrm{bp}\end{array}$ \\
\hline Mn-SOD C47T & $\begin{array}{l}\text { 5'-GCTGTGCTTTCTCGTCTTCAG-3' } \\
\text { 5'-TGGTACTTCTCCTCGGTGACG-3' }\end{array}$ & BsawI & $57^{\circ} \mathrm{C}$ & $\begin{array}{l}\text { C allele } 267 \mathrm{bp}, \mathrm{T} \text { allele } 183 \\
\text { and } 84 \mathrm{bp}\end{array}$ \\
\hline CAT $-21 \mathrm{~A} / \mathrm{T}$ & $\begin{array}{l}\text { 5'-AATCAGAAGGCAGTCCTCCC-3' } \\
\text { 5'-TCGGGGAGCACAGAGTGTAC-3' }\end{array}$ & HinfI & $60^{\circ} \mathrm{C}$ & $\begin{array}{l}\text { A allele } 203 \text { and } 47 \mathrm{bp} \\
\text { T allele } 250 \mathrm{bp}\end{array}$ \\
\hline
\end{tabular}

\section{Statistical data}

Quantitative data are reported as mean \pm standard deviation and were compared using the unpaired Student $t$-test analysis. Qualitative data are expressed in percentages and were compared using the $\chi^{2}$ test. Genotype frequency differences in $\mathrm{Cu} / \mathrm{Zn}-\mathrm{SOD}+35 \mathrm{~A} / \mathrm{C}[\mathrm{CC} / \mathrm{C}$ carriers $v s$ AA (reference group)], Mn-SOD T47C [CC/C carriers $v s$ TT (reference group)], and CAT $-21 \mathrm{~A} / \mathrm{T}[\mathrm{TT} / \mathrm{T}$ carriers $v s \mathrm{AA}$ (reference group)] between groups were examined by the Pearson $\chi^{2}$ test. ORs with their corresponding 95\%CI were calculated. Polyphenol excretion was compared in the different groups between genotypes of $\mathrm{Cu} / \mathrm{Zn}-\mathrm{SOD}+35 \mathrm{~A} / \mathrm{C}[\mathrm{CC} / \mathrm{C}$ carriers $v s$ AA (reference group)], Mn-SOD T47C [CC/C carriers $v s$ TT (reference group)], and CAT $-21 \mathrm{~A} / \mathrm{T}[\mathrm{TT} / \mathrm{T}$ carriers $v$ s AA (reference group)] using the unpaired Student $t$-test. A $\mathrm{P}<0.05$ was considered to be statistically significant. All statistical analyses were undertaken using the SPSS version 17 software.

\section{RESULTS}

Comparisons between green tea consumption groups in term of biological parameters are shown in Table 2. The biological parameters showed significant differences in the markers 
of oxidative stress: uric acid $(\mathrm{P}=0.04)$ and MDA $(\mathrm{P}<0.01)$, which significantly decreased among the high consumers group ( $\mathrm{N}$ cups $>3$ ). UPD was significantly higher among high consumers $(\mathrm{P}=0.03)$.

The genotype distribution of $\mathrm{Cu} / \mathrm{Zn}-\mathrm{SOD}+35 \mathrm{~A} / \mathrm{C}, \mathrm{Mn}-\mathrm{SOD}$ T47C, and CAT -21 A/T according to diabetes complications and tea consumption are presented in Table 3. Among the high tea consumers ( $\mathrm{N}$ cups $>3$ ) subgroup, the Mn-SOD T47C CC genotype frequency was higher in non-complicated diabetics $(0.13)$ compared with complicated diabetics $(0.32$, $\mathrm{P}=0.03 ; \mathrm{OR}=0.284 ; 95 \% \mathrm{CI}=0.086-0.939)$. However, no differences were observed in the genotypic distribution of $\mathrm{Cu} / \mathrm{Zn}-\mathrm{SOD}+35 \mathrm{~A} / \mathrm{C}[\mathrm{CC} v s \mathrm{AA}$ and $(\mathrm{CC}+\mathrm{CA})$ s $\mathrm{AA}]$ and CAT -21 $\mathrm{A} / \mathrm{T}[\mathrm{TT} v s \mathrm{AA}$ and $(\mathrm{TT}+\mathrm{TA})$ vs $\mathrm{AA}]$ between complicated and non-complicated T2D.

The UPD comparison between $\mathrm{Cu} / \mathrm{Zn}-\mathrm{SOD}+35 \mathrm{~A} / \mathrm{C}$, Mn-SOD T47C, and CAT -21 A/T genotypes is shown in Table 4. No statistical differences were revealed in the distribution of UPD levels between genotypes tested, excepting in the high tea consumers subgroup. Among the latter, the Mn-SOD T47C CC genotype-carrying individuals showed a significantly higher UPD level $(4.77 \pm 3.42 \mathrm{mg} / 100 \mathrm{~mL})$ compared with TT genotype-carrying subjects $(3.79 \pm 3.09 \mathrm{mg} / 100 \mathrm{~mL}, \mathrm{P}=0.038)$.

Table 2. Anthropometric, clinical, and biochemical characteristics of subjects based on tea intake.

\begin{tabular}{|c|c|c|c|c|}
\hline & \multirow[t]{2}{*}{ Patients $(\mathrm{N}=366)$} & \multicolumn{2}{|c|}{ Tea consumption } & \multirow[t]{2}{*}{$\mathrm{P}$} \\
\hline & & $\mathrm{N}$ cups $<3(\mathrm{~N}=226)$ & $\mathrm{N}$ cups $>3(\mathrm{~N}=140)$ & \\
\hline Age (years) & $54.33 \pm 9.38$ & $54.05 \pm 9.42$ & $54.89 \pm 9.32$ & - \\
\hline Gender $(\mathrm{M} / \mathrm{F})$ & $153 / 213$ & $86 / 140$ & $67 / 73$ & - \\
\hline BMI $\left(\mathrm{kg} / \mathrm{m}^{2}\right)$ & $30.41 \pm 5.39$ & $30.41 \pm 5.44$ & $30.41 \pm 5.30$ & - \\
\hline Current smoker & & & & - \\
\hline Yes (\%) & 17.5 & 16.7 & 18.9 & \\
\hline No $(\%)$ & 82.5 & 83.3 & 81.2 & \\
\hline Duration of diabetes (years) & $10.18 \pm 6.62$ & $11.05 \pm 6.34$ & $10.45 \pm 7.21$ & - \\
\hline Physical activity & & & & - \\
\hline Yes (\%) & 31.7 & 33.1 & 28.9 & \\
\hline No $(\%)$ & 68.3 & 66.9 & 71.1 & \\
\hline Treatment & & & & - \\
\hline Insulin (\%) & 78.2 & 79.9 & 74.3 & \\
\hline Oral hypoglycemic drugs (\%) & 11 & 8.7 & 15 & \\
\hline Combination of both (\%) & 10.8 & 11.4 & 10.7 & \\
\hline \multicolumn{5}{|l|}{ Complication } \\
\hline Yes [N (\%)] & $101(27.6)$ & $61(27)$ & $40(28.5)$ & \\
\hline No $[\mathrm{N}(\%)]$ & $265(72.4)$ & $165(73)$ & $100(71.5)$ & 0.72 \\
\hline \multicolumn{5}{|l|}{ Complication type } \\
\hline Retinopathy [N (\%)] & $80(79.2)$ & $46(75.4)$ & $34(85)$ & 0.25 \\
\hline Nephropathy [N (\%)] & $23(22.7)$ & $15(24.6)$ & $8(20)$ & 0.72 \\
\hline Neuropathy $[\mathrm{N}(\%)]$ & $9(8.9)$ & $4(6.5)$ & $5(12.5)$ & 0.3 \\
\hline Systolic blood pressure (mmHg) & $13.49 \pm 2.13$ & $13.5 \pm 2.08$ & $13.47 \pm 2.24$ & 0.91 \\
\hline Diastolic blood pressure ( $\mathrm{mmHg}$ ) & $7.99 \pm 1.19$ & $8.04 \pm 1.12$ & $7.9 \pm 1.32$ & 0.27 \\
\hline Protein $(g / L)$ & $69.95 \pm 9.16$ & $70.43 \pm 9.18$ & $68.97 \pm 9.09$ & 0.15 \\
\hline $\mathrm{HbA}_{\mathrm{c}}(\%)$ & $9.14 \pm 1.81$ & $9.09 \pm 1.83$ & $9.26 \pm 1.77$ & 0.4 \\
\hline Glucose (mM) & $11.36 \pm 3.1$ & $11.28 \pm 3.12$ & $11.52 \pm 3.08$ & 0.49 \\
\hline Total cholesterol (mM) & $4.89 \pm 0.92$ & $4.9 \pm 0.85$ & $4.87 \pm 1.05$ & 0.79 \\
\hline LDL cholesterol (mM) & $2.98 \pm 0.77$ & $2.98 \pm 0.71$ & $2.99 \pm 0.87$ & 0.89 \\
\hline HDL cholesterol (mM) & $1.22 \pm 0.43$ & $1.23 \pm 0.44$ & $1.22 \pm 0.41$ & 0.84 \\
\hline Triglycerides (mM) & $1.5 \pm 0.78$ & $1.51 \pm 0.78$ & $1.49 \pm 0.78$ & 0.76 \\
\hline Creatinine $(\mu \mathrm{M})$ & $75.37 \pm 19.37$ & $74.97 \pm 19.83$ & $76.2 \pm 18.44$ & 0.56 \\
\hline Uric acid $(\mu \mathrm{M})$ & $250.77 \pm 73.37$ & $256.04 \pm 75.45$ & $240.13 \pm 68.05$ & $0.04 *$ \\
\hline $\operatorname{MDA}(\mathrm{mM})$ & $4.2 \pm 1.97$ & $5.31 \pm 2.13$ & $3.03 \pm 1.7$ & $<0.01 * *$ \\
\hline UPD (mg/100 mL) & $3.49 \pm 2.56$ & $3.16 \pm 2.29$ & $3.8 \pm 2.83$ & $0.03 *$ \\
\hline
\end{tabular}


Table 3. $\mathrm{Cu} / \mathrm{Zn} \mathrm{SOD}, \mathrm{Mn}-\mathrm{SOD}$, and CAT genotypes according to diabetes complication and tea consumption.

\begin{tabular}{|c|c|c|c|c|c|c|c|c|c|}
\hline \multirow[b]{2}{*}{$\mathrm{Cu} / \mathrm{Zn}$ SOD genotypes } & \multicolumn{3}{|c|}{ All $(\mathrm{N}=366)$} & \multicolumn{3}{|c|}{ Tea cups $<3(\mathrm{~N}=226)$} & \multicolumn{3}{|c|}{ Tea cups $>3(\mathrm{~N}=140)$} \\
\hline & AA & $\mathrm{CA}$ & $\mathrm{CC}$ & AA & $\mathrm{CA}$ & $\mathrm{CC}$ & AA & $\mathrm{CA}$ & $\mathrm{CC}$ \\
\hline $\begin{array}{l}\text { Without complication } \\
(\mathrm{N}=265)(\%)\end{array}$ & $181(0.68)$ & $59(0.22)$ & $25(0.09)$ & $113(0.68)$ & $34(0.22)$ & $18(0.1)$ & $68(0.68)$ & $25(0.25)$ & $7(0.07)$ \\
\hline $\begin{array}{l}\text { With complication } \\
(\mathrm{N}=101)(\%)\end{array}$ & $72(0.71)$ & $21(0.20)$ & $8(0.08)$ & $43(0.7)$ & $12(0.19)$ & $6(0.1)$ & $29(0.72)$ & $9(0.22)$ & $2(0.05)$ \\
\hline $\mathrm{P}$ & & $0.58^{\mathrm{b}}$ & $0.61^{\mathrm{a}}$ & & $0.77^{b}$ & $0.79^{\mathrm{a}}$ & & $0.6^{\mathrm{b}}$ & $0.62^{\mathrm{a}}$ \\
\hline Mn-SOD genotypes & $\mathrm{CC}$ & CT & TT & $\mathrm{CC}$ & CT & TT & $\mathrm{CC}$ & CT & TT \\
\hline $\begin{array}{l}\text { Without complication } \\
(\mathrm{N}=265)(\%)\end{array}$ & $79(0.29)$ & $139(0.54)$ & $47(0.17)$ & $47(0.28)$ & $91(0.55)$ & $27(0.17)$ & $32(0.32)$ & $48(0.48)$ & $20(0.20)$ \\
\hline $\begin{array}{l}\text { With complication } \\
(\mathrm{N}=101)(\%)\end{array}$ & $25(0.25)$ & $52(0.51)$ & $24(0.24)$ & $20(0.33)$ & $28(0.46)$ & $13(0.21)$ & $5(0.13)$ & $24(0.6)$ & $11(0.27)$ \\
\hline $\mathrm{P}$ & $0.15^{\mathrm{c}}$ & $0.19^{\mathrm{d}}$ & & $0.77^{\mathrm{c}}$ & $0.38^{\mathrm{d}}$ & & $0.03^{e *}$ & $0.33^{\mathrm{d}}$ & \\
\hline CAT genotypes & AA & AT & TT & AA & AT & TT & AA & AT & TT \\
\hline $\begin{array}{l}\text { Without complication } \\
(\mathrm{N}=265)(\%)\end{array}$ & $64(0.24)$ & $143(0.54)$ & $58(0.21)$ & $43(0.26)$ & $83(0.50)$ & $39(0.23)$ & $21(0.21)$ & $60(0.60)$ & $19(0.19)$ \\
\hline $\begin{array}{l}\text { With complication } \\
(\mathrm{N}=101)(\%)\end{array}$ & $24(0.23)$ & $51(0.50)$ & $26(0.26)$ & $18(0.29)$ & $27(0.44)$ & $16(0.26)$ & $6(0.15)$ & $24(0.60)$ & $10(0.25)$ \\
\hline $\mathrm{P}$ & & $0.93^{f}$ & $0.59^{\circ}$ & & $0.6^{\mathrm{f}}$ & $0.96^{\mathrm{e}}$ & & $0.41^{\mathrm{f}}$ & $0.31^{\mathrm{e}}$ \\
\hline
\end{tabular}

Table 4. Comparison of urinary polyphenol derivative levels $(\mathrm{mg} / 100 \mathrm{~mL})$ between $\mathrm{Cu} / \mathrm{Zn} \mathrm{SOD}, \mathrm{Mn}-\mathrm{SOD}$, and CAT genotypes according to tea consumption.

\begin{tabular}{|c|c|c|c|c|c|c|}
\hline \multirow[t]{2}{*}{ Genotypes } & \multirow[t]{2}{*}{ Patients $(\mathrm{N}=366)$} & \multirow[t]{2}{*}{$P$} & \multicolumn{4}{|c|}{ Tea consumption } \\
\hline & & & $\mathrm{N}$ cups $<3(\mathrm{~N}=226)$ & $P$ & $\mathrm{~N}$ cups $>3(\mathrm{~N}=140)$ & $P$ \\
\hline \multicolumn{7}{|c|}{$\overline{\mathrm{Cu} / \mathrm{Zn} \mathrm{SOD}}$} \\
\hline AA & $3.19 \pm 2.27$ & & $2.84 \pm 2.03$ & & $3.56 \pm 2.51$ & \\
\hline $\mathrm{CC}$ & $3.67 \pm 2.41$ & 0.342 & $3.31 \pm 2.05$ & 0.352 & $4.02 \pm 2.79$ & 0.307 \\
\hline $\mathrm{CC}+\mathrm{AC}$ & $3.12 \pm 2.56$ & 0.815 & $2.83 \pm 2.3$ & 0.914 & $3.44 \pm 2.72$ & 0.696 \\
\hline \multicolumn{7}{|l|}{ Mn-SOD } \\
\hline TT & $3.51 \pm 2.76$ & & $3.2 \pm 2.34$ & & $3.79 \pm 3.09$ & \\
\hline $\mathrm{CC}$ & $4.13 \pm 3.26$ & 0.082 & $3.54 \pm 2.7$ & 0.406 & $4.77 \pm 3.42$ & $0.038^{*}$ \\
\hline $\mathrm{CC}+\mathrm{CT}$ & $3.81 \pm 2.88$ & 0.36 & $3.37 \pm 2.38$ & 0.567 & $4.24 \pm 3.31$ & 0.286 \\
\hline \multicolumn{7}{|l|}{ CAT } \\
\hline AA & $3.69 \pm 2.57$ & & $3.45 \pm 2.28$ & & $3.93 \pm 2.86$ & \\
\hline TT & $3.14 \pm 2.2$ & 0.239 & $2.86 \pm 2.14$ & 0.113 & $3.46 \pm 2.27$ & 0.353 \\
\hline $\mathrm{TT}+\mathrm{TA}$ & $3.22 \pm 2.42$ & 0.307 & $3.03 \pm 2.28$ & 0.284 & $3.49 \pm 2.62$ & 0.374 \\
\hline
\end{tabular}

$\mathrm{Cu} / \mathrm{Zn}$ SOD AA, Mn-SOD TT, and CAT AA genotypes are taken as reference groups. $* \mathrm{P}<0.05$.

\section{DISCUSSION}

SOD and CAT constitute the initial antioxidant defense system that removes toxic free radicals and maintains the redox balance (Laddha et al., 2013). Allelic variation in $\mathrm{Cu} /$ Zn-SOD has been implicated in human disorders, particularly kidney disease, diabetes, and hypertension (Heink et al., 2013). The $+35 \mathrm{~A} / \mathrm{C}$ polymorphism in $\mathrm{Cu} / \mathrm{Zn}-\mathrm{SOD}$ is adjacent to the splicing point (exon3/intron3) and is related to $\mathrm{Cu} / \mathrm{Zn}$-SOD activity with AA genotype having the higher activity (Panduru et al., 2010). Our data showed no association between $\mathrm{Cu} / \mathrm{Zn}-\mathrm{SOD}+35 \mathrm{~A} / \mathrm{C}$ polymorphism and T2D complications. In contrast to type 1 diabetes (T1D), the association of this variation with T2D has been poorly documented. Panduru et al. (2010) illustrate an association of the C-mutant allele in the $\mathrm{Cu} / \mathrm{Zn}$-SOD gene with advanced 
stages of diabetic nephropathy in patients with T1D in Romania. Other studies have found multiple associations between $\mathrm{Cu} / \mathrm{Zn}$-SOD single nucleotide polymorphisms (SNPs) and the persistence of micro albuminuria, and the prevalence of diabetic nephropathy and retinopathy in T1D subjects (Al-Kateb et al., 2008; Mohammedi et al., 2011).

With regard to the CAT gene and T2D, one of the widely discussed catalase gene polymorphisms, CAT $-21 \mathrm{~A} / \mathrm{T}$, which is located in the promoter region just proximal to the transcription start site, was investigated in our population. Our results did not show any relationship between CAT $-21 \mathrm{~A} / \mathrm{T}$ allelic variants and diabetes complication. In contrast, it has been reported that the mutant TT genotype is associated with hyperglycemia, hypercholesterolemia, and reduced catalase concentration, compared to the CC genotype in Hungarian T2D (Góth and Nagy, 2013).

In the Mn-SOD encoding gene, the T47C SNP, inducing the substitution from valine to alanine (V16A) at the 16th amino acid position in the second exon [also known as (V-9A) at position 9 in the signal peptide of human Mn-SOD], changes the structural conformation of the mitochondrial targeting sequence of the enzyme from an $\alpha$-helix (A variant) to a $\beta$-sheet (V variant). This substitution may lead to misdirected intracellular trafficking inducing a 30$40 \%$ decrease in mitochondrial Mn-SOD activity and contributing to the accumulation of ROS (Chistyakov et al., 2001). It has been reported that the altered Mn-SOD variant increases the risk of oxidative stress associated with various pathologies, including diabetic microvascular disease (Chistyakov et al., 2001; Lee and Choi, 2006; Eras-Erdogan et al., 2009; Chen et al., 2012). Mn-SOD may be the most important member of the SOD family; therefore, people presenting Mn-SOD gene mutations are subjected to lower Mn-SOD efficiency and might be more prone to complications (Kariž et al., 2012; Montano et al., 2012). In our study, we found that the Mn-SOD CC genotype may protect against the development of complications in Tunisian T2D. This result is consistent with those of Chistyakov et al. (2001) who found that V Mn-SOD was associated with diabetic neuropathy in a Russian population. It was observed that the TT genotype of this variant is associated with increased coronary heart disease risk in Caucasian females but not males with diabetes (Jones et al., 2010). Moreover, another study demonstrated that $\mathrm{V}$ Mn-SOD contributes to the development of diabetic retinopathy in Chinese T2D patients (Ye et al., 2008). However, these findings were not supported by Dutkiewicz et al. (2010) who did not observe an association of the V Mn-SOD gene with renal complications in diabetes mellitus. Furthermore, Lee and Choi (2006) have demonstrated that the V16A polymorphism of the Mn-SOD gene is not related to the development of diabetes and the progression of diabetic retinopathy, but is associated with diabetic macular edema in Korean T2D patients. A recent meta-analysis including 17 articles revealed that the $\mathrm{C}$ allele of the T47C polymorphism in the Mn-SOD gene protects against diabetic nephropathy and retinopathy (Tian et al., 2011).

We reported an Mn-SOD CC genotype protective effect against T2D complications only among a high tea consumer ( $\mathrm{N}$ cups $>3$ ) subgroup $(\mathrm{P}=0.03$; $\mathrm{OR}=0.284 ; 95 \% \mathrm{CI}=0.086$ 0.939 ), whereas the association between the Mn-SOD CC genotype and complication progression was not significant in the patients studied as a whole $(\mathrm{P}=0.15)$. This might be attributed to a combined effect of gene polymorphisms and tea intake in complication prevention. Indeed, the health benefits of tea consumption are well known (Khan and Mukhtar, 2007; Anhê et al., 2013).

In the high tea consumer group, uric acid and MDA were significantly lower than in the moderate tea consumer group, suggesting that high tea consumption is beneficial in the reduction of oxidative stress in T2D. The polyphenolic fraction of green tea was proposed as a possible candidate for diabetes prevention. Here, it is important to remember that most 
polyphenolic compounds are present in food in the form of esters, glycosides, or polymers. It has to be acknowledged that these compounds must be converted to derivative metabolites in the intestinal lumen before they can be absorbed. During the course of absorption, polyphenols are conjugated in the small intestine and the liver (Manach et al., 2004). This process mainly includes methylation, sulfation, and glucuronidation, which restricts the toxic effects of polyphenol derivatives and facilitates their biliary and urinary elimination. Enterohepatic recycling may lead to a longer retention of derivative metabolites within the body (Manach et al., 2004). Polyphenol derivatives are able to penetrate tissues to exert their beneficial effects (van Duynhoven et al., 2011). Furthermore, an interaction between antioxidant enzyme genetic variants and tea polyphenols might explain this protective effect. Indeed, there have been many studies investigating the interactions between tea polyphenols and metabolizing enzymes. An administration of green tea polyphenols to alloxan diabetic rats indicated decreased lipid peroxidation associated with increased SOD and GST levels, whereas catalase was unchanged (Sabu et al., 2002). It has also been reported that the incubation of cultured rat brain astrocytes with catechins increases SOD (Cu/Zn-SOD and Mn-SOD subtypes) expression and activity (Chan et al, 2002). Similarly, Mori and Hasegawa (2003) have demonstrated that an addition of green tea to adipocytes enhances SOD activity.

In our study, we also analyzed the association between the metabolizing enzyme gene polymorphisms $\mathrm{Cu} / \mathrm{Zn}-\mathrm{SOD}+35 \mathrm{~A} / \mathrm{C}$, Mn-SOD T47C, and CAT $-21 \mathrm{~A} / \mathrm{T}$ and UPD rates, as a marker of polyphenols intake. To our knowledge, this is the first study examining the association between UPD, SOD, and CAT polymorphisms in relation to T2D complications. No straight association between UPD and diabetic complications was established $(\mathrm{P}>0.05)$ (data not shown). However, genotype analysis only showed significantly higher UPD levels in the Mn-SOD T47C $\mathrm{CC}$ genotype-carrying individuals in the high tea consumers group $(\mathrm{P}=0.038)$, whereas significance was not reached in patients as a whole $(\mathrm{P}=0.082)$. Such interactions between UPDs and metabolizing enzymes in relation to disease risk have been investigated previously. Luo et al. (2012) found that the inverse association between flavonols and epigallocatechin in urine and breast cancer risk only appeared among those null for glutathione S transferase (GST) GSTM1, particularly null for both GSTM1 and GSTT1. The authors explained that for those null for GSTM1 and GSTT1 genes, the epigallocatechin may alternatively activate other cancer inhibitory GST forms. Another explanation could be that polyphenols may be more slowly excreted in urine among those null for GSTM1 and GSTT1, leading to higher bioavailability levels of cancer inhibitory tea polyphenols. With regard to Mn-SOD, it was established that its expression in mitochondria is upregulated by several polyphenolic compounds. Priego et al. (2008) showed that trans-pterostilbene (trans-3,5-dimethoxy-4'-hydroxystilbene) and quercetin (3,3',4',5,6-pentahydroxyflavone) induced an increase in Mn-SOD gene expression in HT-29 tumor-growing cells via an SP1 transcription factor mechanism. Other data have shown that epicatechins from cocoa significantly reduce MnSOD acetylation and nitrotyrosilation, via interaction with SIRT3 protein, leading to enhanced enzymatic activity (Ramirez-Sanchez et al., 2013). The authors also reported that Mn-SOD gene expression is modulated by epicatechins through an SIRT1 nuclear factor mechanism. These interactions between tea polyphenols and the Mn-SOD enzyme may provide an explanation for our findings on enhanced polyphenol excretion among Mn-SOD 47 CC genotype-carrying individuals. A possible explanation is that highly activated Mn-SOD (due to the CC genotype), and the resulting reduced oxidative stress within mitochondria, induces rapid trafficking of polyphenols throughout the body, which may explain the higher polyphenol excretion.

Finally, our study showed that the Mn-SOD 47 CC genotype, in combination with the 
beneficial effects of tea polyphenols, prevents the development of complications in T2D. In addition, we report higher urine polyphenols excretion in Mn-SOD 47 CC genotype-carrying individuals. According to our findings, UPD excretion is further enhanced by a specific genetic background, such as the presence of the Mn-SOD T47C variant described here.

\section{Conflicts of interest}

The authors declare no conflict of interest.

\section{ACKNOWLEDGMENTS}

The authors would like to thank the Ministry of Higher Education and Scientific Research in Tunisia for financial support of this study.

\section{REFERENCES}

Aditi MN, Rawal S and Katare R (2013). An Insight in to the Pathogenesis of Diabetic Vascular Diseases: Role of Oxidative Stress and Antioxidants. Pharmaceut. Anal. Acta 4:10.

Al-Kateb H, Boright AP, Mirea L, Xie X, et al. (2008). Multiple superoxide dismutase 1/splicing factor serine alanine 15 variants are associated with the development and progression of diabetic nephropathy: the Diabetes Control and Complications Trial/Epidemiology of Diabetes Interventions and Complications Genetics study. Diabetes 57: 218-228.

Anhê FF, Desjardins Y, Pilon G, Dudonné S, et al. (2013). Polyphenols and type 2 diabetes: A prospective review. Pharma Nutrition 1: 105-114.

Ascencio-Montiel IJ, Parra EJ, Valladares-Salgado A, Gómez-Zamudio JH, et al. (2013). SOD2 gene Val16Ala polymorphism is associated with macroalbuminuria in Mexican Type 2 Diabetes patients: a comparative study and meta-analysis. BMC Med. Genet. 14: 110.

Bahadoran Z, Mirmiran P and Azizi F (2013). Dietary polyphenols as potential nutraceuticals in management of diabetes: a review. J. Diabetes Metab. Disord. 12: 43.

Chan P, Cheng JT, Tsai JC, Lien GS, et al. (2002). Effect of catechin on the activity and gene expression of superoxide dismutase in cultured rat brain astrocytes. Neurosci. Lett. 328: 281-284.

Chen H, Yu M, Li M, Zhao R, et al. (2012). Polymorphic variations in manganese superoxide dismutase (MnSOD), glutathione peroxidase-1 (GPX1), and catalase (CAT) contribute to elevated plasma triglyceride levels in Chinese patients with type 2 diabetes or diabetic cardiovascular disease. Mol. Cell Biochem. 363: 85-91.

Chistyakov DA, Savost'anov KV, Zotova EV and Nosikov VV (2001). Polymorphisms in the Mn-SOD and EC-SOD genes and their relationship to diabetic neuropathy in type 1 diabetes mellitus. BMC Med. Genet. 2: 4.

Crawford A, Fassett RG, Geraghty DP, Kunde DA, et al. (2012). Relationships between single nucleotide polymorphisms of antioxidant enzymes and disease. Gene 501: 89-103.

Dhaouadi K, Fattouch S and Hamdaoui MH (2010). Extraction, identification and quantification of the polyphenols of green and black Tunisian tea decoctions commercialized as "Garden of tea". Acta Hoticulturae 853: 199-206.

Dutkiewicz G, Domanski L, Pawlik A, Binczak-Kuleta A, et al. (2010). Polymorphisms of superoxide dismutase, glutathione peroxidase and catalase genes in patients with post-transplant diabetes mellitus. Arch. Med. Res. 41: 350-355.

Eras-Erdogan N, Akbas E, Senli H, Kul S, et al. (2009). Relationship between polymorphism in the manganese superoxide dismutase gene and breast cancer. Mutat. Res. 680: 7-11.

Forsberg L, de Faire U and Morgenstern R (2001). Oxidative stress, human genetic variation, and disease. Arch. Biochem. Biophys. 389: 84-93.

Góth L and Nagy T (2013). Inherited catalase deficiency: is it benign or a factor in various age related disorders? Mutat. Res. 753: 147-154.

Guérin P, El Mouatassim S and Ménézo Y (2001). Oxidative stress and protection against reactive oxygen species in the pre-implantation embryo and its surroundings. Hum. Reprod. Update 7: 175-189.

Heink AE, Parrish AN, Thorgaard GH and Carter PA (2013). Oxidative stress among SOD-1 genotypes in rainbow trout (Oncorhynchus mykiss). Aquat. Toxicol. 144-145: 75-82. 
InterAct Consortium, van Woudenbergh GJ, Kuijsten A, Drogan D, et al. (2012). Tea consumption and incidence of type 2 diabetes in Europe: the EPIC-InterAct case-cohort study. PLoS One 7: e36910.

Jones DA, Prior SL, Tang TS, Bain SC, et al. (2010). Association between the rs4880 superoxide dismutase 2 (C $>$ T) gene variant and coronary heart disease in diabetes mellitus. Diabetes Res. Clin. Pract. 90: 196-201.

Kariž S, Nikolajević Starčević J and Petrovič D (2012). Association of manganese superoxide dismutase and glutathione S-transferases genotypes with myocardial infarction in patients with type 2 diabetes mellitus. Diabetes Res. Clin. Pract. 98: 144-150.

Khan N and Mukhtar H (2007). Tea polyphenols for health promotion. Life Sci. 81: 519-533.

Laddha NC, Dwivedi M, Gani AR, Shajil EM, et al. (2013). Involvement of superoxide dismutase isoenzymes and their genetic variants in progression of and higher susceptibility to vitiligo. Free Radic. Biol. Med. 65: 1110-1125.

Lee SJ and Choi MG (2006). Association of manganese superoxide dismutase gene polymorphism (V16A) with diabetic macular edema in Korean type 2 diabetic patients. Metabolism 55: 1681-1688.

Luo J, Gao YT, Chow WH, Shu XO, et al. (2012). Urinary polyphenols, glutathione S-transferases copy number variation, and breast cancer risk: results from the Shanghai women's health study. Mol. Carcinog. 51: 379-388.

Manach C, Scalbert A, Morand C, Rémésy C, et al. (2004). Polyphenols: food sources and bioavailability. Am. J. Clin. Nutr. 79: 727-747.

Mohammedi K, Maimaitiming S, Emery N, Bellili-Muñoz N, et al. (2011). Allelic variations in superoxide dismutase-1 (SOD1) gene are associated with increased risk of diabetic nephropathy in type 1 diabetic subjects. Mol. Genet. Metab. 104: 654-660.

Montano MA, da Cruz IB, Duarte MM, Krewer Cda C, et al. (2012). Inflammatory cytokines in vitro production are associated with Ala16Val superoxide dismutase gene polymorphism of peripheral blood mononuclear cells. Cytokine 60: 30-33.

Mori M and Hasegawa N (2003). Superoxide dismutase activity enhanced by green tea inhibits lipid accumulation in 3T3L1 cells. Phytother. Res. 17: 566-567.

Neves AL, Mohammedi K, Emery N, Roussel R, et al. (2012). Allelic variations in superoxide dismutase-1 (SOD1) gene and renal and cardiovascular morbidity and mortality in type 2 diabetic subjects. Mol. Genet. Metab. 106: 359-365.

Ohkawa H, Ohishi N and Yagi K (1979). Assay for lipid peroxides in animal tissues by thiobarbituric acid reaction. Anal. Biochem. 95: 351-358.

Panduru NM, Cimponeriu D, Cruce M, Ion DA, et al. (2010). Association of +35A/C (intron3/exon3) polymorphism in SOD1-gene with diabetic nephropathy in type 1 diabetes. Rom. J. Morphol. Embryol. 51: 37-41.

Poljsak B, Šuput D and Milisav I (2013). Achieving the Balance between ROS and Antioxidants: When to Use the Synthetic Antioxidants. Oxid. Med. Cell Longev. 2013: 956-792.

Priego S, Feddi F, Ferrer P, Mena S, et al. (2008). Natural polyphenols facilitate elimination of HT-29 colorectal cancer xenografts by chemoradiotherapy: a Bcl-2- and superoxide dismutase 2-dependent mechanism. Mol. Cancer Ther. 7: 3330-3342.

Ramirez-Sanchez I, Taub PR, Ciaraldi TP, Nogueira L, et al. (2013). (-)-Epicatechin rich cocoa mediated modulation of oxidative stress regulators in skeletal muscle of heart failure and type 2 diabetes patients. Int. J. Cardiol. 168: 3982-3990.

Sabu MC, Smitha K and Kuttan R (2002). Anti-diabetic activity of green tea polyphenols and their role in reducing oxidative stress in experimental diabetes. J. Ethnopharmacol. 83: 109-116.

Singleton VL and Rossi JA (1965). Colorimetry of total phenolics with phosphomolybdic-phosphotungstic acid reagents. Am. J. Enol.Viticult. 16: 144-158.

Tian C, Fang S, Du X and Jia C (2011). Association of the C47T polymorphism in SOD2 with diabetes mellitus and diabetic microvascular complications: a meta-analysis. Diabetologia 54: 803-811.

van Duynhoven J, Vaughan EE, Jacobs DM, Kemperman RA, et al. (2011). Metabolic fate of polyphenols in the human superorganism. Proc. Natl. Acad. Sci. U. S. A. 108: 4531-4538.

Villeneuve LM and Natarajan R (2010). The role of epigenetics in the pathology of diabetic complications. Am. J. Physiol. Renal. Physiol. 299: F14-F25.

Ye LX, Yang MP, Qiu H, Guo KQ, et al. (2008). Association of the polymorphism in manganese superoxide dismutase gene with diabetic retinopathy in Chinese type 2 diabetic patients. Zhonghua Yi Xue Yi Chuan Xue Za Zhi 25: 452454.

Zhang Y, Zhang L, Sun DL, Li ZS, et al. (2011). Genetic polymorphisms of superoxide dismutases, catalase, and glutathione peroxidase in age-related cataract. Mol. Vis. 17: 2325-2332. 